\title{
Effect of chemical mixing state on the hygroscopicity and cloud nucleation properties of calcium mineral dust particles
}

\author{
R. C. Sullivan ${ }^{1,}$, M. J. K. Moore ${ }^{1}$, M. D. Petters ${ }^{2}$, S. M. Kreidenweis ${ }^{2}$, G. C. Roberts $^{3}$, and K. A. Prather ${ }^{1,3}$ \\ ${ }^{1}$ Department of Chemistry and Biochemistry, University of California, San Diego, La Jolla, CA, 92093, USA \\ ${ }^{2}$ Department of Atmospheric Science, Colorado State University, Fort Collins, CO, 80523, USA \\ ${ }^{3}$ Scripps Institution of Oceanography, University of California, San Diego, La Jolla, CA, 92093, USA \\ * currently at: Department of Atmospheric Science, Colorado State University, Fort Collins, CO, 80523, USA
}

Received: 11 December 2008 - Published in Atmos. Chem. Phys. Discuss.: 28 January 2009

Revised: 29 April 2009 - Accepted: 5 May 2009 - Published: 20 May 2009

\begin{abstract}
Atmospheric mineral dust particles can alter cloud properties and thus climate by acting as cloud condensation nuclei $(\mathrm{CCN})$ that form cloud droplets. The $\mathrm{CCN}$ activation properties of various calcium mineral dust particles were studied experimentally to investigate the consequences of field observations showing the segregation of sulphate from nitrate and chloride between individual aged Asian dust particles, and the enrichment of oxalic acid in Asian dust. Each mineral's observed apparent hygroscopicity was primarily controlled by its solubility, which determines the degree to which the mineral's intrinsic hygroscopicity can be expressed. The significant increase in hygroscopicity caused by mixing soluble hygroscopic material with insoluble mineral particles is also presented. Insoluble minerals including calcium carbonate, representing fresh unprocessed dust, and calcium sulphate, representing atmospherically processed dust, had similarly small apparent hygroscopicities. Their activation is accurately described by a deliquescence limit following the Kelvin effect and corresponded to an apparent single-hygroscopicity parameter, $\kappa$, of $\sim 0.001$. Soluble calcium chloride and calcium nitrate, representing atmospherically processed mineral dust particles, were much more hygroscopic, activating similar to ammonium sulphate with $\kappa \sim 0.5$. Calcium oxalate monohydrate $(\kappa=0.05)$ was significantly less $\mathrm{CCN}$-active than oxalic acid $(\kappa=0.3)$, but not as inactive as its low solubility would predict. These results indicate that the common assumption that all mineral dust particles become more hygroscopic and
\end{abstract}

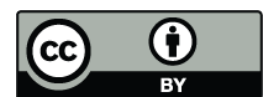

Correspondence to: K. A. Prather (kprather@ucsd.edu)
$\mathrm{CCN}$-active after atmospheric processing should be revisited. Calcium sulphate and calcium oxalate are two realistic proxies for aged mineral dust that remain non-hygroscopic. The dust's apparent hygroscopicity will be controlled by its chemical mixing state, which is determined by its mineralogy and the chemical reaction pathways it experiences during transport.

\section{Introduction}

Atmospheric aerosols affect the formation, growth, and lifetime of clouds by acting as cloud condensation nuclei (CCN) that provide seeds for cloud droplet formation (McFiggans et al., 2006). Increased number concentrations of CCN can increase cloud brightness (Twomey, 1977), change cloud lifetime (Albrecht, 1989), and suppress (Lohmann and Feichter, 2005; Rosenfeld et al., 2001) or enhance precipitation (Petters et al., 2006; Rosenfeld et al., 2008). The interactions of aerosols and clouds remain the largest uncertainties in our ability to understand and predict the effect that anthropogenic activities have on regional and global climate change (IPCC, 2007). A particle's ability to absorb enough water such that it activates and becomes a cloud droplet is governed primarily by the particle's size and its soluble hygroscopic chemical content (McFiggans et al., 2006). Therefore, the size-resolved chemical composition and mixing state of atmospheric aerosols, and a detailed knowledge of how different compounds interact with water, are required to accurately predict how a realistic aerosol population will undergo cloud nucleation (Andreae and Rosenfeld, 2008; McFiggans et al., 2006).

Published by Copernicus Publications on behalf of the European Geosciences Union. 
Most inorganic salts present in aerosols (e.g. $\left(\mathrm{NH}_{4}\right)_{2} \mathrm{SO}_{4}$, $\mathrm{NaCl}$ ) are hygroscopic and $\mathrm{CCN}$-active at sub $100 \mathrm{~nm}$ diameters and typical cloud supersaturations. However, the role of insoluble and slightly soluble inorganic salts should also be considered and studied for their $\mathrm{CCN}$ activation properties (Kelly et al., 2007). The conversion of insoluble salts to more soluble compounds through heterogeneous and multiphase reactions is of particular interest. Mineral dust particles are the most atmospherically relevant example of these types of inorganic systems. To date, only a few laboratory studies have been reported of the $\mathrm{CCN}$ properties of model mineral dust particles (Gibson et al., 2006). Koehler et al. (2007) measured the first $\mathrm{CCN}$ activation curves of an authentic dust sample, salt-rich playa dust from Owens (dry) Lake in California. Recently Koehler et al. (2009) reported the hygroscopicity of three other mineral dust samples and concluded that they could be described by a hygroscopicity parameter of $0.01 \leq \kappa \leq 0.08$. Vlasenko et al. (2005) reported that Arizona test dust had very small subsaturated hygroscopic growth. A few studies have recently been reported probing the role that ambient mineral dust particles play in contributing to aerosol hygroscopicity and $\mathrm{CCN}$ formation (Carrico et al., 2003; Perry et al., 2004; Roberts et al., 2006; Shi et al., 2008). Twohy et al. (2009) recently demonstrated that Saharan dust particles commonly act as CCN over the eastern North Atlantic. Mineral dust particles are also some of the most efficient ice nuclei (DeMott et al., 2003; Stith et al., 2009). Their freezing properties are strongly dependent on mineralogy (Eastwood et al., 2008; Zimmermann et al., 2008), and can be altered by the addition of secondary compounds from atmospheric processing.

Mineral dust close to the source region is composed of a large and variable mixture of different minerals. This can include insoluble aluminosilicate clays (e.g. kaolinite, montmorilinite, illite), metal oxides (e.g. hematite, silica), carbonates (e.g. calcite, dolomite), and sparingly soluble gypsum $\left(\mathrm{CaSO}_{4} \cdot 2 \mathrm{H}_{2} \mathrm{O}\right)$, as well as soluble halite $(\mathrm{NaCl})$ salts (Claquin et al., 1999; Jeong, 2008; Krueger et al., 2004; Shi et al., 2005; Sullivan et al., 2007a). These mineral components often undergo chemical reactions during atmospheric transport, such as reactions with $\mathrm{SO}_{2}(\mathrm{~g})$ to produce sulphate, $\mathrm{HCl}(\mathrm{g})$ producing condensed-phase chloride, and nitrogen oxides such as $\mathrm{NO}_{2}(\mathrm{~g}), \mathrm{HNO}_{3}(\mathrm{~g})$, and $\mathrm{N}_{2} \mathrm{O}_{5}(\mathrm{~g})$ to produce nitrate compounds (Krueger et al., 2004; Sullivan et al., 2007a, b; Usher et al., 2003). Reaction of dust with organic compounds such as carboxylic acids is also possible (Falkovich et al., 2004; Sullivan and Prather, 2007). Mineral dust particles can also accumulate soluble material through internal mixing with sea salt particles during cloud processing (Sullivan et al., 2007b), and condensation of compounds including ammonium nitrate and sulphate. Kelly et al. (2007) recently reported theoretical calculations predicting a wide range of $\mathrm{CCN}$ properties due to the differing water soluble fraction of the various components of mineral dust.
Calcite $\left(\mathrm{CaCO}_{3}(\mathrm{~s})\right)$ is generally regarded to be the most chemically reactive mineral component in aeolian dust particles (Laskin et al., 2005; Tang et al., 2004; Usher et al., 2003). It is present at significant levels (at least $5-10 \%$ by mass) in the surface soils of most of the major global dust sources, including the Northern Saharan and Arabian deserts, the Gobi and Taklimakan deserts in Asia, and the Thar desert in India (Claquin et al., 1999). These compose the largest and most persistent dust sources, referred to as the "dust belt". $\mathrm{CaCO}_{3}$ can be found in the form of individual mostly-calcite particles, and also as calcite nanofibers distributed throughout mineral dust particles (Jeong and Chun, 2006). Its strong alkaline nature causes it to react readily with acidic gases including $\mathrm{HNO}_{3}, \mathrm{HCl}$, and $\mathrm{SO}_{2}$. This converts calcium carbonate to other calcium salts such as calcium nitrate, calcium chloride, and calcium sulphate, respectively. The conversion of insoluble calcium carbonate particles to deliquescent calcium nitrate through reaction with nitric acid vapour was first demonstrated in laboratory experiments by Krueger et al. $(2003,2004)$ and has also been observed in recent field studies (Laskin et al., 2005; Matsuki et al., 2005; Shi et al., 2008). Gibson et al. (2006) demonstrated the large effect that this conversion has on the $\mathrm{CCN}$ activation of laboratory calcium mineral particles; the critical supersaturation of $100 \mathrm{~nm}$ calcium nitrate particles was $0.11 \%$ compared to $\sim 0.55 \%$ for atomized $100 \mathrm{~nm}$ calcium carbonate particles. Mineral dust populations can also indirectly affect $\mathrm{CCN}$ number populations through physical processes, for example by altering gas-particle partitioning, or coagulating with existing $\mathrm{CCN}-$ active particles (Lee et al., 2009).

The addition of soluble material such as nitric and sulphuric acids and their ammonium salts, and the conversion of carbonates to more soluble compounds during atmospheric processing of mineral dust particles is commonly believed to increase the CCN activity of these particles (Fan et al., 2004; Gibson et al., 2006; Levin et al., 1996; Perry et al., 2004; Roberts et al., 2006; Sullivan et al., 2007a). From our singleparticle measurements of atmospherically processed mineral dust particles during ACE-Asia, we observed that nitrate and sulphate were not found in relatively large amounts in the same individual dust particles (Sullivan et al., 2007a). We hypothesized that this segregated mixing state of secondary acids could impart very different physicochemical properties to individual aged dust particles, particularly in terms of their interaction with water, due to the large solubility differences between some sulphate and nitrate salts. Oxalic acid was also found to be enriched in the Asian mineral dust particles and we hypothesized that the formation of complexes between oxalate and divalent cations such as $\mathrm{Ca}^{2+}$ could reduce the solubility of the dominant fraction of water soluble organic carbon (Sullivan and Prather, 2007). We explore both of these hypotheses herein through laboratory studies of the CCN activation properties of various pure calcium minerals as proxies for fresh and completely processed calcium carbonate particles. The important effect of water and 
metastable hydrate formation on the hygroscopicity of calcium minerals produced by the particle generation method is the focus of a related manuscript (Sullivan et al., 2009).

\section{Experimental methods}

\subsection{Aerosol generation}

Commercially available calcium salts were used to generate particles for these experiments. They included $\mathrm{CaCO}_{3}$ (Solvay, uncoated ultrafine Socal ${ }^{\circledR} 31$, unstated purity), $\mathrm{CaSO}_{4}$ (Aldrich, 99\%), $\mathrm{Ca}\left(\mathrm{NO}_{3}\right)_{2}$ (Alfa Aesar, 99.0+\%), $\mathrm{CaCl}_{2} \cdot 2 \mathrm{H}_{2} \mathrm{O}$ (Aldrich, 98+\%), $\mathrm{CaC}_{2} \mathrm{O}_{4} \cdot \mathrm{H}_{2} \mathrm{O}$ (Alfa Aesar, $99+\%$ ), and $\mathrm{C}_{2} \mathrm{O}_{4} \mathrm{H}_{2}$ (Aldrich, 99+\%). The wet-generation method involved atomization of aqueous solutions using high purity $\mathrm{N}_{2}$ at $2-3 \mathrm{Lpm}$, and then passing the aerosol through three silica gel diffusion driers to reduce the $\mathrm{RH}$ below $5 \%$. $\mathrm{Ca}\left(\mathrm{NO}_{3}\right)_{2}, \mathrm{CaCl}_{2}$, and $\mathrm{C}_{2} \mathrm{O}_{4} \mathrm{H}_{2}$ solutions were made by adding $0.15 \mathrm{~g}$ powder into $150 \mathrm{~mL}$ milli-Q water $\left(>18.2 \mathrm{M} \Omega\right.$ ). Dry generation, used for $\mathrm{CaSO}_{4}, \mathrm{CaCO}_{3}$, and $\mathrm{CaC}_{2} \mathrm{O}_{4} \cdot \mathrm{H}_{2} \mathrm{O}$, involved placing several grams of powder in an Erlenmeyer flask with a Teflon-coated stir bar. A piece of Teflon tubing was passed through a silicone stopper with a plastic pipette tip fitted on the end. When nitrogen gas was passed through the tubing a jet of gas was produced and directed at the powder, while the stir bar or vortex shaker agitated the dry powder. The suspended aerosol was sampled through a $3 / 8^{\prime \prime}$ o.d. stainless steel (s.s.) tube at the top of the flask and then directed into a second Erlenmeyer flask through a s.s. tube with a right angle bend. The aerosol was transferred to a $\sim 17 \mathrm{~L}$ s.s. residence chamber to which dilution nitrogen gas of $2.0-8.0 \mathrm{Lpm}$ was added. The aerosol sample was drawn from two $3 / 8^{\prime \prime}$ o.d. s.s. tubes that protruded slightly into the chamber and then combined into one flow.

\subsection{CCN activation curve measurement}

For both generation methods the dry aerosol was sent to a differential mobility analyzer (DMA, Model 3081, TSI Inc.) for size selection. The aerosol was first passed through a $\mathrm{Kr}-85$ bipolar neutralizer to achieve charge equilibrium. An aerosol sample flow rate of 1.0 or $1.5 \mathrm{Lpm}$ was used, with a sheath flow rate of 10.0 or $15.0 \mathrm{Lpm}$. A 10:1 sheath/sample flow ratio was used whenever possible; however a lower sheath/sample flow ratio was required to select particles as large as $500 \mathrm{~nm}$. The pseudo-monodisperse aerosol was then sent to a flow splitter and transferred to a condensation particle counter (CPC, Model 3010 or 3007, TSI Inc.) and a cloud condensation nuclei counter $(\mathrm{CCNc})$. A small excess aerosol flow of $\sim 0.2 \mathrm{Lpm}$ was vented through a HEPA filter to eliminate any large pressure or flow imbalances. Conductive silicone tubing was used to transport the aerosol and minimize wall losses. A scanning mobility particle sizing (SMPS) sys- tem (TSI Model 3081 DMA and Model 3010 CPC) was used to verify the mode diameter of the size-selected aerosol.

\section{3 $\mathrm{CCN}$ counter $(\mathrm{CCNc})$ operation and calibration}

The $\mathrm{CCNc}$ is a miniature continuous-flow streamwise thermal-gradient $\mathrm{CCN}$ chamber constructed at Scripps Institution of Oceanography based on the design of Roberts and Nenes (2005). Briefly, the aerosol sample is introduced into the centre of the growth column surrounded by a sheath of filtered humidified air. A linear thermal gradient along the column's continuously wetted wall produces a well-defined and controlled water supersaturation. This supersaturation is primarily a function of the column's thermal gradient $(d T)$ and the total flow rate. Particles that are able to absorb water and grow to optical diameters $>1 \mu \mathrm{m}$ are detected by an optical particle counter (OPC) at the end of the column and are counted as $\mathrm{CCN}$. The aerosol flow rate is $15.0 \mathrm{sccm}$ while the sheath flow is adjusted to produce a total flow of 100.0 $\mathrm{sccm}$. A bypass flow of $400 \mathrm{sccm}$ is used to increase the initial sample flow to the top of the column and reduce particle losses.

Calibration of the CCNc's supersaturation (SS) as a function of column temperature gradient $(d T)$ was performed monthly using dried ammonium sulphate particles atomized from a $1.0 \mathrm{~g} / \mathrm{L}$ solution of ammonium sulphate (Sigma, 99.999\%) and determining activation diameter as a function of column $d T$. Köhler theory using thermodynamic data from the aerosol inorganic model (AIM) was used to calculate the supersaturation that corresponded to each activation diameter, assuming spherical particles, to create the $d T$-SS calibration curve. Our choice of thermodynamic data for ammonium sulphate corresponds to a single-parameter hygroscopicity of $\kappa=0.61$ (see below). The linear fits of SS to column $d T$ typically had $R^{2}>0.995$. Column temperature gradients of 2.0 to $15.0^{\circ} \mathrm{C}$ generated SS of approximately 0.08 to $1.1 \%$.

\subsection{Data analysis and fitting}

CCN activation curves were generated either by scanning across dry particle diameter $\left(D_{\text {dry }}\right)$ at a fixed SS, or by scanning SS (through changing $d T$ ) at a fixed dry diameter. Both the $\mathrm{CCNc}$ and $\mathrm{CPC}$ record 1-s averaged data, which were averaged to one minute for calculation of the $\mathrm{CCN} / \mathrm{CN}$ ratio. For both SS and size scans we determined the critical activation diameter $\left(D_{\text {act }}=D_{\text {dry }}\right)$ or critical supersaturation $\left(s_{c}\right)$ by first scaling all ratios to the maximum observed CCN/CN ratio, for large sizes/high supersaturations. The contribution from larger multiply charged particles was then accounted for following Rose et al. (2008). A Boltzman sigmoid curve of the form

$y=\frac{A_{1}-A_{2}}{1+e^{\left(x-x_{o}\right) / d x}}-A_{2}$ 
was used to fit each activation curve, where $y$ is the $\mathrm{CCN} / \mathrm{CN}$ ratio, $A_{1}$ is the minimum value, $A_{2}$ is the maximum value, $d x$ is the rate of change, and $x_{o}$ is the midpoint between $A_{1}$ and $A_{2}$. The data were fit such that $A_{1}$ corresponded to the $\mathrm{CCN} / \mathrm{CN}$ ratio of the multiply charged particles at small sizes/supersaturations, and $A_{2}$ is set to the scaled maximum $\mathrm{CCN} / \mathrm{CN}$ ratio of $\sim 1.0$. Thus, $x_{o}$ corresponds to the $\mathrm{CCN} / \mathrm{CN}=0.5$ midpoint typically used to define the critical supersaturation or activation diameter of the singly-charged particles of interest. We note that this technique is more accurate for SS scans, because the fraction of multiply charged particles larger than the selected dry diameter is constant for all points, and the assumption of constant composition with size, implicit in diameter scans, is not as important. SS scans are slower than size scans, however, because the column must equilibrate to the new temperature gradient, and thus size scans were used for some experiments. The contributions of multiply charged particles to the activation curve in size scans can be explicitly calculated using the inversion proposed by Petters et al. (2007). Although we did not use that method to reduce all of our size-scan data, we verified via spot checks that our simpler method did not give significantly different results from the full inversion.

\subsection{Error analysis}

The major sources of uncertainty in determining the $\mathrm{CCN}$ activation properties, critical supersaturation $\left(s_{c}\right)$ and dry (activation) diameter $\left(D_{\mathrm{dry}}\right)$, are primarily due to the calibration of the CCNc's supersaturation, and errors in selecting a monodisperse aerosol with the DMA. The SS uncertainty was estimated from the linear fit of the $\mathrm{CCNc}$ calibration as $3 \%$. Uncertainty in size selection was estimated as $5 \%$, including variations in particle shape factor and flow rates, and from SMPS measurements of the size-selected aerosol. The error reported for the fitted hygroscopicity parameter, $\kappa$ (see below), was estimated from one standard deviation of the $\kappa$ values determined from the individual $s_{c}-D_{\text {dry }}$ pairs for each system.

\section{Results and discussion}

\subsection{Hygroscopicity parameter}

We have expressed all of our experimental data in terms of the hygroscopicity parameter, $\kappa$, introduced by Petters and Kreidenweis (2007), which describes a particle's water activity, $a_{w}$, via

$$
\frac{1}{a_{w}}=1+\kappa \frac{V_{s}}{V_{w}}
$$

where $V_{s}$ is the volume of the dry particle mass and $V_{w}$ is the volume of water. A choice of dry diameter $\left(D_{\mathrm{dry}}\right)$ and $\kappa$ enable calculation of the expected supersaturation - wet diameter relationship ("Köhler curve"):

$$
S(D)=\frac{D^{3}-D_{\text {dry }}^{3}}{D^{3}-D_{\text {dry }}^{3}(1-\kappa)} \exp \left(\frac{A}{D}\right),
$$

where $S$ is the water saturation ratio over the aqueous droplet, $D$ is the droplet diameter, and $A=2.1 \times 10^{-9} \mathrm{~m}$ is a constant evaluated for a surface tension of $0.072 \mathrm{~J} \mathrm{~m}^{-2}$ (pure water) and temperature of $298.15 \mathrm{~K}$; the exponential term is the Kelvin term from the Köhler equation. Unless otherwise stated we assume a surface tension of pure water in all cases when deriving $\kappa$. The maximum in the curve described by Eq. (3) is identified as the critical saturation ratio for activation of the chosen dry diameter (critical supersaturation, $s_{c}=S-1$ ). The best-fit hygroscopicity parameter that describes the observed behaviour of test particles can be determined using Eq. (3) by computing Köhler curves for iterations of $\kappa$ until the modelled $s_{c}$ for a selected dry diameter matches the experimentally observed $s_{c}$.

Kappa increases with increasing hygroscopicity, from 0 to a maximum of $\sim 1.4 ; \mathrm{NaCl}$ has $\kappa=1.28$, for example. We denote the $\kappa$ value that is derived from measured $s_{c}$ - $D_{\text {dry }}$ pairs and Eq. (3) as apparent hygroscopicity, or $\kappa_{\text {app}}$, while the $\kappa$ value that is obtained from Eq. (2) is the intrinsic hygroscopicity, or $\kappa_{\text {intr }}$, for an aqueous particle. Apparent and intrinsic hygroscopicities are equal when the particle is fully dissolved at the water content relevant to $\mathrm{CCN}$ activation. Particles composed of compounds with limited solubility can reduce the observed $\kappa_{\text {app }}$ below $\kappa_{\text {intr }}$. Similarly, surface tension effects can cause $\kappa_{\text {app }}$ to differ significantly from $\kappa_{\text {intr }}$.

It is important to properly distinguish between the roles of solubility and hygroscopicity. While hygroscopicity determines the ability of a particle to absorb water, only the compound's dissolved mass fraction contributes to hygroscopic growth. Insoluble components lower the $s_{c}$ required for activation by increasing the particle's diameter and thus reducing the Kelvin term in Eq. (3), but cannot participate in hygroscopic growth. Therefore, particles composed of intrinsically hygroscopic but insoluble compounds will exhibit a very small apparent hygroscopicity and poor $\mathrm{CCN}$ activity. As many of the minerals used in this study have limited solubility in water, we applied an extension of Eq. (3) proposed by Petters and Kreidenweis (2008), where the following equations are used to compute $\kappa$ :

$$
\begin{aligned}
\kappa_{\text {sum }}(D) & =\sum_{i} \varepsilon_{i} \kappa_{i} H\left(x_{i}\right) \\
x_{i} & =\left(\left(D / D_{\mathrm{dry}}\right)^{3}-1\right) C_{i} / \varepsilon_{i} \\
H\left(x_{i}\right) & = \begin{cases}x_{i} & x_{i}<1 \\
1 & x_{i}>1\end{cases}
\end{aligned}
$$

Equation $(4 \mathrm{a}-\mathrm{c})$ have been written to allow for multiple components, $i$, where $\varepsilon_{i}$ is the volume fraction of component 


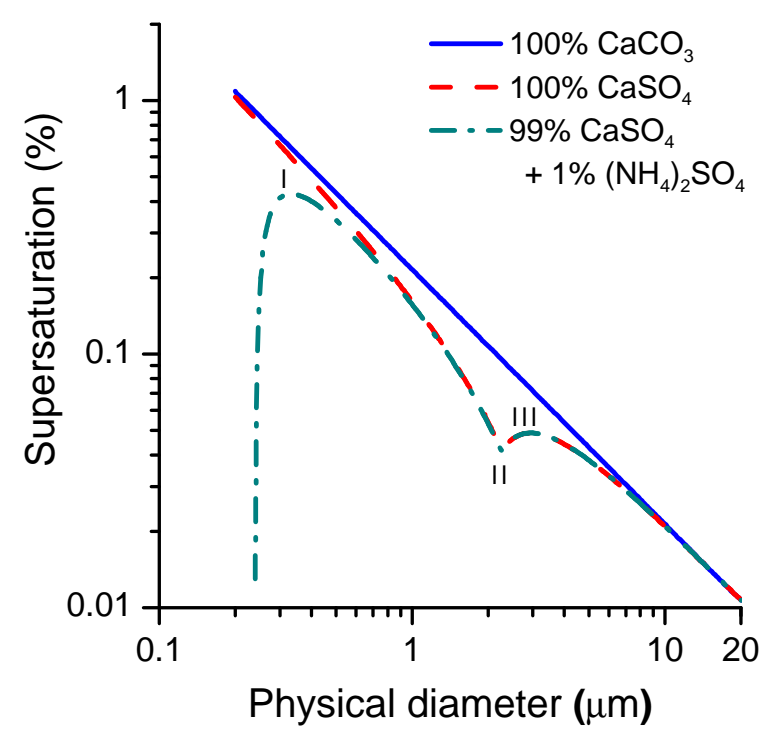

Fig. 1. Theoretical $\kappa$-Köhler droplet growth curves for $200 \mathrm{~nm}$ dry $\mathrm{CaCO}_{3}$ and $\mathrm{CaSO}_{4}$ particles calculated using Eqs. (3-4). A mixed $200 \mathrm{~nm}$ particle composed of $99 \% \mathrm{CaSO}_{4}$ and $1 \%\left(\mathrm{NH}_{4}\right)_{2} \mathrm{SO}_{4}$ ( $\kappa_{\text {intr }}=0.6, C=0.43$ ) by volume is also shown. The solubilities and intrinsic hygroscopicities $\left(\kappa_{\text {intr }}\right)$ used are from Table 1. I: activation of the mixed particle before complete dissolution of the $\mathrm{CaSO}_{4}$ core, II: complete dissolution of $\mathrm{CaSO}_{4}$, III: second supersaturaion maximum corresponds to $s_{c}$ of an equivalent metastable liquid droplet. $s_{c}$ of pure $\mathrm{CaCO}_{3}$ and $\mathrm{CaSO}_{4}=1.03 \%$, while the mixed $\mathrm{CaSO}_{4}$ particle has $s_{c}=0.429 \%$.

$i$ in the dry particle, $C_{i}$ the solubility of $i$ in water (expressed as volume compound per unit volume of water), and $H$ is an index for the fraction of component $i$ that has dissolved, $x_{i}$. In Eq. (4a) the individual $\kappa_{i}$ are intrinsic hygroscopicities for each compound and $\kappa_{\text {sum }}(D)$ is used in Eq. (3) to find the maximum of the Köhler curve. It is important to distinguish $\kappa_{\text {sum }}(D)$ which varies with droplet size, $D$, and the associated water content, from the constant $\kappa_{\text {app}}$, which is fit to observed $s_{c}-D_{\text {dry }}$ pairs.

Figure 1 shows representative Köhler growth curves computed from Eqs. (3-4) for two of the insoluble minerals studied in this work. The curves demonstrate that, for species with limited solubility, some ranges of $D$ represent water contents that are insufficient to dissolve the entire compound present in the dry particle. Both of these pure $200 \mathrm{~nm}$ particles are predicted to activate at $s_{c} \sim 1 \%$, the critical supersaturation required for an insoluble and thus nonhygroscopic but wettableparticle $\left(\kappa_{\mathrm{app}} \sim 0\right)$ of the selected dry diameter. The large $s_{c}$ is the result of the compound's low solubility which results in the deliquescence relative humidity exceeding the critical supersaturation of an equivalent metastable solution droplet. Such particles thus activate under a deliquescencelimitation (Kreidenweis et al., 2006) and the activation of such insoluble particles is predominantly determined by the Kelvin term in Eq. (3).
Whether a particle expresses its intrinsic hygroscopicity at activation, or activates at some apparent hygroscopicity depends on $\kappa_{\text {intr }}$, solubility, particle phase, and initial dry diameter. The apparent hygroscopicity is that which is expected to manifest both experimentally and in the atmosphere. Figure 2 displays the apparent hygroscopicity that would be deduced from a measured $s_{c}-D_{\text {dry }}$ pair as a function of the solubility of the primary compound in the particle. The two cases are for an intrinsic hygroscopicity of $\kappa_{\text {intr }}=1.0$ (left panel) and $\kappa_{\text {intr }}=0.050$ (right panel). The contours show that as the compound's solubility increases a larger fraction of its intrinsic hygroscopicity will be observed as its apparent hygroscopicity, until the solubility limit is exceeded and the full intrinsic hygroscopicity is expressed. We show calculations for three particle sizes. The smallest particle sizes have a reduced apparent hygroscopicity at relatively high solubilities. This is because the higher supersaturations required to deliquesce smaller particles, due to an increased Kelvin effect, are interpreted as lower hygroscopicity (Kreidenweis et al., 2006). Thus, for a solubility at which larger particles may express their $\kappa_{\text {app }}=\kappa_{\text {intr }}$ during activation, the critical supersaturation observed for smaller particles might appear close to the $\kappa_{\text {app }}=0$ isoline (Kelvin limit for insoluble but wettable particles). The larger the intrinsic hygroscopicity of the primary component, the smaller the solubility at which this deliquescence limitation is observed.

The presence of sufficiently soluble contaminant that is in solution reduces the solubility where intrinsic and apparent hygroscopicities diverge, as shown by the grey lines in Fig. 2 . The presence of the $1 \% \kappa_{\text {intr }}=0.6$ contaminant limits the smallest apparent $\kappa$ value that can be observed experimentally; for the cases considered here, this limit is at $\kappa_{\text {app }}=0.006$ $(=0.6 \times 1 \%$, Eq. $4 a)$. The contaminant also allows the intrinsic hygroscopicity of the primary component to be expressed at lower solubilities than for single-component particles. This is because the presence of the sufficiently soluble contaminant assures that there is always some water associated with the particle that can dissolve at least a portion of the limited-solubility primary component. We note that the presence of the trace contaminant also modifies the apparent hygroscopicity observed when the particle is fully dissolved at activation. For the case where the primary component was assumed to have $\kappa_{\text {intr }}=0.05$, the observed hygroscopicity at complete dissolution is slightly larger $\left(\kappa_{\mathrm{app}}=0.0555\right)$ in the presence of the contaminant, as predicted from the mixing rule for $\kappa$ (Eq. $4 \mathrm{a})$.

The effect of a $1 \%$ by volume $\left(\mathrm{NH}_{4}\right)_{2} \mathrm{SO}_{4}$ impurity on the Köhler curve for a $200 \mathrm{~nm} \mathrm{CaSO}_{4}$ particle is shown in Fig. 1. The presence of this soluble and hygroscopic minor component removes the deliquescence-limitation experienced by pure $\mathrm{CaSO}_{4}$ because the $\left(\mathrm{NH}_{4}\right)_{2} \mathrm{SO}_{4}$ fraction deliquesces at subsaturated RH. This ensures that there is always a dissolved component present capable of absorbing water, and also causes some of the $\mathrm{CaSO}_{4}$ core to dissolve before activation. This reduces $s_{c}$ from $1.03 \%$ to $0.429 \%$, 


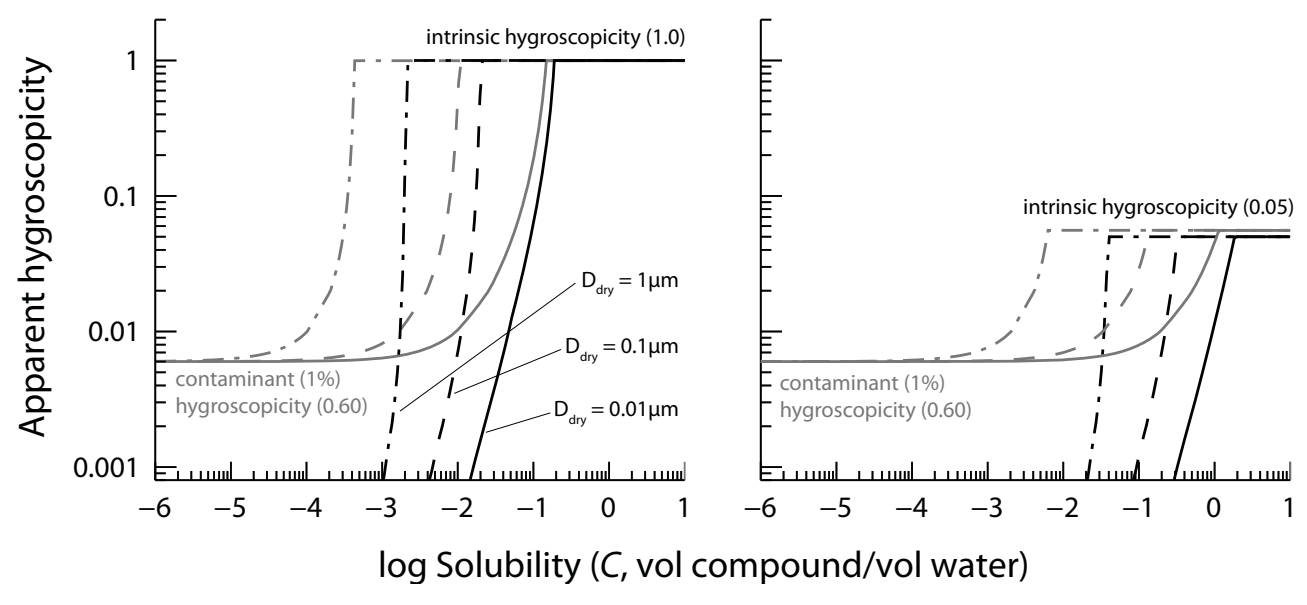

Fig. 2. Predicted apparent hygroscopicity contours for particles composed of a principle compound with $\kappa_{\text {intr }}=1.0$ (left) or 0.050 (right) as a function of the compound's solubility, $C$, and dry particle size. Grey contours are for mixed particles composed of $99 \%$ volume principle compound and $1 \%$ contaminant with $\kappa_{\text {intr }}=0.60$ and $C=\infty$.

occurring at the first maximum in the growth curve (point I), and $\kappa_{\text {app }}$ at activation is increased from 0 to 0.0075 . The second maximum (point III) occurs after the $\mathrm{CaSO}_{4}$ core has fully dissolved (at point II) and corresponds to the critical supersaturation of the completely aqueous $\left(\mathrm{NH}_{4}\right)_{2} \mathrm{SO}_{4} / \mathrm{CaSO}_{4}$ mixed particle. This is analogous to the descriptions of the Köhler curve used to model activation of limited-solubility components in mixed organic-inorganic particles (Bilde and Svenningsson, 2004; Broekhuizen et al., 2004; Petters and Kreidenweis, 2008; Shulman et al., 1996).

Based on Fig. 2 we delineate three solubility regimes:

1) "Sufficiently soluble compounds" are those that have $C>\sim 10^{-1}$ and are soluble enough that $\kappa_{\text {app }}=\kappa_{\text {intr }}$ for all dry particle sizes. Therefore $\mathrm{CaCl}_{2}, \mathrm{Ca}\left(\mathrm{NO}_{3}\right)_{2}$, and $\mathrm{C}_{2} \mathrm{O}_{4} \mathrm{H}_{2}$ are expected to activate according to $\kappa_{\text {intr }}$.

2) "Sparingly soluble compounds" are those where $\kappa_{\text {app }}$ can take any value between $\sim 0$ and $\kappa_{\text {intr }}$. An approximate range is $10^{-4}<C<10^{-1}$.

3) "Insoluble compounds" are those for which $\kappa_{\mathrm{app}} \sim 0$ always applies, i.e. $C<\sim 10^{-4}$. $\mathrm{CaCO}_{3}, \mathrm{CaSO}_{4}$, and $\mathrm{CaC}_{2} \mathrm{O}_{4} \cdot \mathrm{H}_{2} \mathrm{O}$ (Table 1) are thus not expected to express their large intrinsic hygroscopicities, either experimentally or during cloud nucleation. As particles composed of low solubility compounds undergo reactions/processes both in the laboratory and atmosphere that either convert the compounds into more soluble forms, or add soluble hygroscopic material to the particles, the modified particles will express a larger apparent hygroscopicity.
The intrinsic hygroscopicity of a limited-solubility compound, expressed once it is fully dissolved, is difficult to measure, but it can be approximated assuming Raoult's Law applies:

$\kappa_{\mathrm{intr}}=\frac{v \times \rho_{s} \times M_{w}}{\rho_{w} \times M_{s}}$,

where $\rho$ is the density and $M$ the molecular weight of the solute, $s$, and of water, $w$, and $v$ is the number of ions and molecules produced when one molecule of the solute completely dissociates. Table 1 summarizes the properties of the calcium salts considered here. It includes estimates of the intrinsic and apparent hygroscopicities of each compound, the latter estimated for a $200 \mathrm{~nm}$ particle, a typical particle size used in this work, and an amount of soluble contaminant equivalent to the compound's stated purity.

\subsection{Experimentally determined hygroscopicities}

Representative experimentally determined activation curves for each compound are shown in Figs. 3-4, using SS-scans to obtain critical supersaturations for fixed dry diameters. All of the $D_{\mathrm{dry}}-s_{c}$ data obtained in this study, and the best-fit $\kappa$ for each data point, are listed in Table 2. Averaged observed values of $\kappa_{\text {app }}$ are summarized for each compound in Table 1.

For calcium chloride, calcium nitrate, and oxalic acid only wet-generated particles were studied (Fig. 3). Because these compounds are sufficiently soluble, we expect $\kappa_{\text {app }}=\kappa_{\text {intr }}$ listed in Table 1 . The observed $s_{c}$ - $D_{\text {dry }}$ relationships of these particle types are $\kappa_{\text {app }}=0.48 \pm 0.07$, $0.51 \pm 0.07$, and $0.50 \pm 0.05$ respectively, similar to ammonium sulphate $\left(\kappa_{\mathrm{app}}=\kappa_{\mathrm{intr}}=0.61\right)$. The particles were likely composed of hydrates (e.g. $\mathrm{CaCl}_{2} \cdot 2 \mathrm{H}_{2} \mathrm{O}, \mathrm{Ca}\left(\mathrm{NO}_{3}\right)_{2} \cdot 4 \mathrm{H}_{2} \mathrm{O}$, and $\mathrm{C}_{2} \mathrm{O}_{4} \mathrm{H}_{2} \cdot 2 \mathrm{H}_{2} \mathrm{O}$ ) (Kelly and Wexler, 2005) after atomization because the rapid drying process causes those metastable 
Table 1. Properties of minerals ${ }^{\mathrm{a}}$ studied in this work, including predicted and measured hygroscopicities.

\begin{tabular}{|c|c|c|c|c|c|c|c|c|c|}
\hline \multirow[t]{2}{*}{ compound } & \multirow{2}{*}{$\begin{array}{l}\rho \\
\mathrm{g} \mathrm{cm}^{-3}\end{array}$} & \multirow{2}{*}{$\begin{array}{l}M_{S} \\
\mathrm{~g} \mathrm{~mol}^{-1}\end{array}$} & \multirow[t]{2}{*}{$v$} & \multirow{2}{*}{$\begin{array}{l}S \\
\mathrm{gL}^{-1}\end{array}$} & \multirow{2}{*}{$\begin{array}{l}\text { C } \\
\text { vol sol/vol water }\end{array}$} & \multicolumn{2}{|c|}{ predicted $\kappa$} & \multirow[t]{2}{*}{ experimental $\kappa_{\text {app }}$} & \multirow[t]{2}{*}{ notes } \\
\hline & & & & & & intrinsic $^{\mathrm{b}}$ (Raoult) & apparent $^{\mathrm{c}}$ & & \\
\hline $\mathrm{CaCl}_{2}$ & 2.15 & 110.98 & 3 & 813 & 0.38 & 1.05 & 1.04 & $0.48 \pm 0.07(\text { wet })^{\mathrm{d}}$ & 0 \\
\hline $\mathrm{CaCl}_{2} \cdot 2 \mathrm{H}_{2} \mathrm{O}$ & $1.85^{\mathrm{e}}$ & 147.02 & 3 & 813 & 0.44 & 0.68 & 0.68 & & 1 \\
\hline $\mathrm{Ca}\left(\mathrm{NO}_{3}\right)_{2}$ & 2.5 & 164.09 & 3 & 1440 & 0.576 & 0.82 & 0.82 & $0.51 \pm 0.07$ (wet) & 2 \\
\hline $\mathrm{Ca}\left(\mathrm{NO}_{3}\right)_{2} \cdot 4 \mathrm{H}_{2} \mathrm{O}$ & $1.86^{e}$ & 236.09 & 3 & 1440 & 0.774 & 0.43 & 0.43 & & 0 \\
\hline $\mathrm{CaSO}_{4}$ & 2.96 & 136.14 & 2 & 2.05 & $6.9 \times 10^{-4}$ & 0.78 & 0.0084 & $0.0016 \pm 0.0005($ dry $)$ & 0 \\
\hline $\mathrm{CaSO}_{4} \cdot 2 \mathrm{H}_{2} \mathrm{O}$ & 2.32 & 172.20 & 2 & 2.05 & $8.8 \times 10^{-4}$ & 0.49 & 0.0078 & & 3 \\
\hline $\mathrm{CaCO}_{3}$ (calcite) & 2.71 & 100.09 & 2 & $0.0058^{f}$ & $2.1 \times 10^{-6}$ & 0.97 & 0.0068 & $0.0011 \pm 0.0004$ (dry) & 4 \\
\hline $\mathrm{CaC}_{2} \mathrm{O}_{4}$ & 2.2 & 128.10 & 2 & 0.0061 & $2.8 \times 10^{-6}$ & 0.62 & 0.0060 & $0.048 \pm 0.013($ dry $)$ & 0 \\
\hline $\mathrm{CaC}_{2} \mathrm{O}_{4} \cdot \mathrm{H}_{2} \mathrm{O}$ & $2.12^{\mathrm{e}}$ & 146.12 & 2 & 0.0061 & $2.9 \times 10^{-6}$ & 0.52 & 0.0060 & & 5 \\
\hline $\mathrm{C}_{2} \mathrm{O}_{4} \mathrm{H}_{2}$ & 1.90 & 90.04 & 3 & 143 & $7.5 \times 10^{-2}$ & 1.14 & 1.14 & $0.50 \pm 0.05$ (wet) & 3 \\
\hline $\mathrm{C}_{2} \mathrm{O}_{4} \mathrm{H}_{2} \cdot 2 \mathrm{H}_{2} \mathrm{O}$ & 1.653 & 126.07 & 3 & 143 & $8.7 \times 10^{-2}$ & 0.71 & 0.71 & & 0 \\
\hline
\end{tabular}

a Density and solubility taken from the CRC Handbook of Physics and Chemistry, $88^{\text {th }}$ Edition, for $25^{\circ} \mathrm{C}$, except where noted below.

b Calculated using Eq. (5).

${ }^{\mathrm{c}}$ For $200 \mathrm{~nm}$ particles of specified compound, with $0.1 \%-2 \%$ impurity (see notes) having $\kappa_{\text {intr }}=0.6$ and infinite solubility.

d Wet- or dry-generated laboratory particles.

e Manufacturer stated value.

${ }^{\mathrm{f}}$ Plummer and Busenberg (1982).

Notes:

0 . Assumed purity of $99 \%$ 3. Aldrich, $99+\%$

1. Aldrich, $98+\%$ 4. Solvay, assumed purity $99 \%$

2. Alfa Aesar, $99.0+\% \quad$ 5. Alfa Aesar, 99+

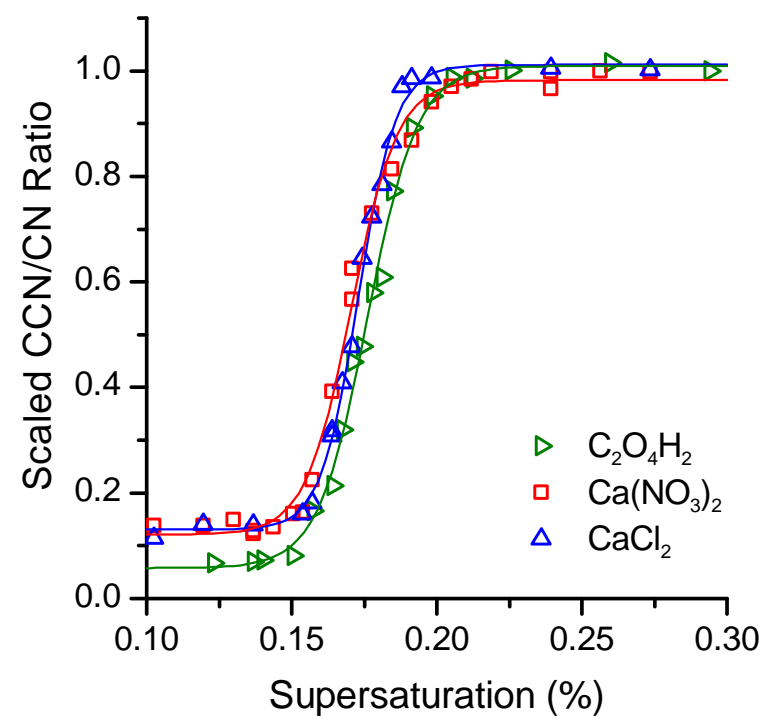

Fig. 3. $\mathrm{CCN}$ activation curves for atomized oxalic acid $\left(s_{C}=0.176 \%\right)$, calcium chloride $\left(s_{c}=0.173 \%\right)$, and calcium nitrate $\left(s_{C}=0.171 \%\right)$ from supersaturation scans of $100.0 \mathrm{~nm}$ mobility diameter particles. Lines are sigmoidal fits between the scaled lower and upper plateaus. The CCN column's supersaturation is derived from the column's temperature gradient by calibration with ammonium sulphate aerosol.

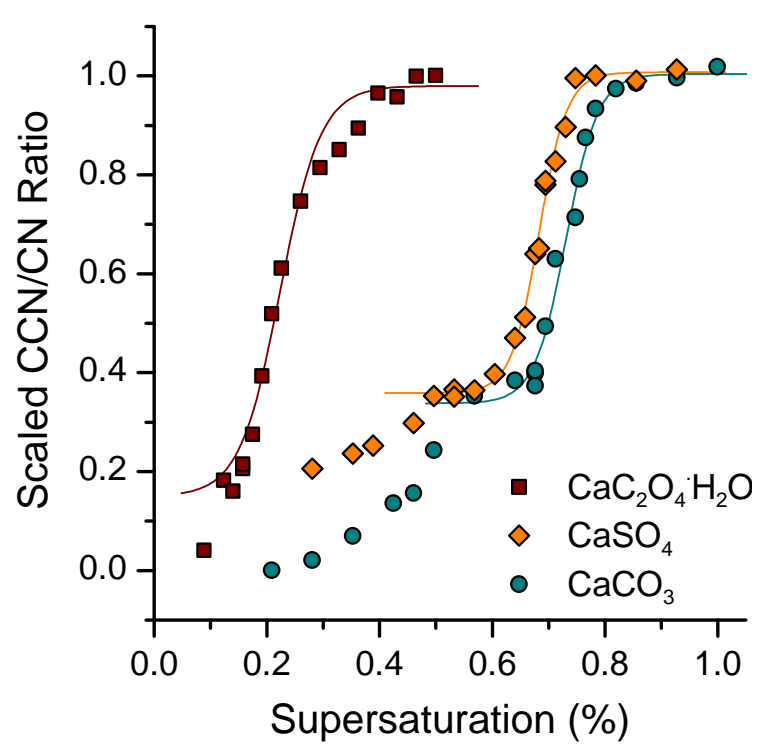

Fig. 4. CCN activation curves of dry-generated calcium carbonate, calcium sulphate, and calcium oxalate monohydrate aerosol obtained by scanning supersaturation of $200.0 \mathrm{~nm}$ dry mobility diameter particles. Lines are sigmodal fits to each curve. Note the lack of a clear multiply-charged plateau in the calcium oxalate monohydrate curve. 
states to be locked in. However, we cannot exclude the possibility that the stable anhydrous (Tang and Fung, 1997) or glassy states (Cohen et al., 1987) formed after drying the particles. Koehler et al. (2006) observed that the hygroscopicity of atomized oxalic acid was generally most consistent with the formation of the dihydrate in typical laboratory atomization/drying processes. As indicated in Table 1, the calculated intrinsic $\kappa$ values for the hydrated compounds are lower than for the anhydrous compounds, and correspond well to our measurements. Our results also compare reasonably well with those of Gibson et al. (2006) for calcium nitrate. They found $s_{c}=0.11 \%$ and estimated the dry diameter of their $100 \mathrm{~nm}$ particles to be $89 \mathrm{~nm}$ due to incomplete particle drying, corresponding to $\kappa_{\text {app }}=1.25$ (Table 2).

Calcium carbonate, calcium sulphate, and calcium oxalate monohydrate were studied using two different particle generation methods: atomization from an aqueous suspension/solution, and resuspension of the dry powder. The wetgenerated $\mathrm{CaCO}_{3}$ aerosol had a geometric mode diameter of $\sim 40 \mathrm{~nm}$, while the dry-generated aerosol peaked $\sim 300 \mathrm{~nm}$. The wet-generated particles from these insoluble powders all produced apparent hygroscopicities much larger than the expected $\kappa_{\text {app }}$ considering their very low solubility. The causes of this unexpected behaviour are investigated in a related manuscript (Sullivan et al., 2009). For the purposes of this study, only the dry-generated particles that produced the appropriate observed hygroscopicity expected of fresh atmospheric mineral particles are considered here.

Dry-generated $\mathrm{CaSO}_{4}$ particles exhibited a small $\kappa_{\text {app }}=0.0016 \pm 0.0005$, and $\mathrm{CaCO}_{3}$ displayed $\kappa_{\text {app }}=0.0011 \pm 0.0004$. There was a $\sim 0.4$ fraction of multiply-charged particles in these size-selected aerosols (Fig. 4) due to the dry-generated aerosol's size distribution peaking at a larger diameter than that selected by the DMA. This large fraction agrees with that predicted based on the polydisperse aerosol's size distribution and aerosol charging theory. Gibson et al. (2006) measured $s_{c}$ of atomized $100 \mathrm{~nm} \mathrm{CaCO}_{3}$ to be $\sim 0.55 \%$, corresponding to $\kappa_{\text {app }} \sim 0.043$ (Table 2). This observed hygroscopicity is much larger than expected for an insoluble mineral (Kelly et al., 2007) $\left(\kappa_{\text {app }} \sim 0\right)$ and was likely caused by the atomization particle generation method they used; we have observed similarly large apparent hygroscopicities $\left(\kappa_{\mathrm{app}}=0.002-0.2\right)$ for atomized $\mathrm{CaCO}_{3}$ particles (Sullivan et al., 2009). From our results, we conclude that both $\mathrm{CaSO}_{4}$ and $\mathrm{CaCO}_{3}$ have a sufficiently low solubility that their $\mathrm{CCN}$ activation behaviour can be approximated as that of an insoluble component $\left(\kappa_{\text {app }}=0\right)$ which activates according to the Kelvin effect only. Small amounts of sufficiently soluble contaminants ( $1 \%$ by volume) increase apparent hygroscopicity above 0, as shown in Figs. 2 and 5. The small $\kappa_{\text {app }}$ of $\sim 0.001$ for these dry-generated particles indicates that they likely contained only small quantities of sufficiently soluble impurities $(<1 \%)$, such as inorganic salts. Analysis of the resuspended dry particles using an aerosol time-of-flight

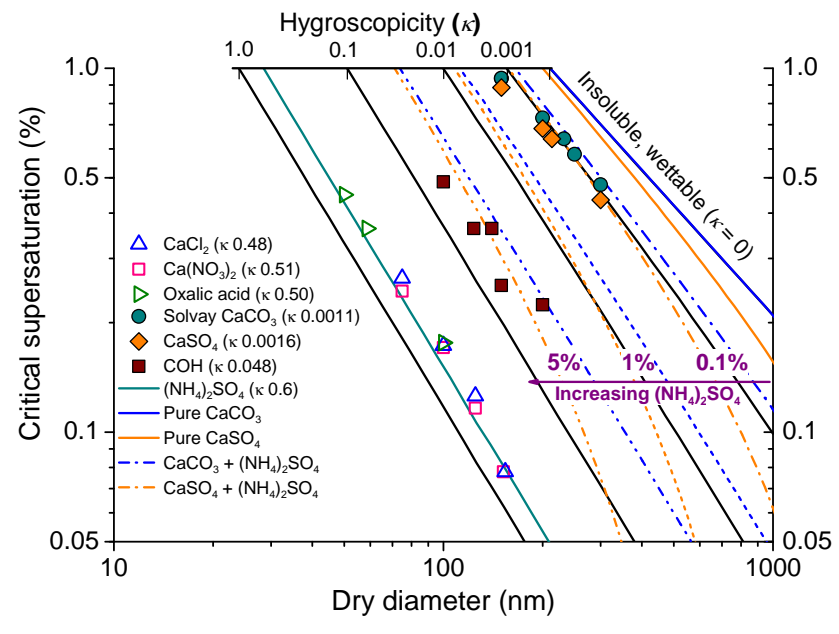

Fig. 5. $s_{c}-D_{\text {dry }}$ relationships with $\kappa$ isolines overlain for drygenerated insoluble calcium minerals (solid symbols) and atomized soluble salts (open symbols). The best-fit $\kappa_{\text {app }}$ values from Table 1 are also listed. Also displayed are predicted $\kappa$ isolines for pure $\mathrm{CaCO}_{3}$ particles (blue lines, $\kappa_{\text {intr }}=0.97, C=2.1 \times 10^{-6}$ ) and $\mathrm{CaSO}_{4}$ particles (orange lines, $\kappa_{\text {intr }}=0.78, C=6.9 \times 10^{-4}$ ), and their internal mixtures (dashed lines) with varying volume fractions of ammonium sulphate $\left(\kappa_{\text {intr }}=0.6, C=0.43\right) .100 \% \mathrm{CaCO}_{3}$ lies along the $\kappa=0$ isoline, and the fraction of $\left(\mathrm{NH}_{4}\right)_{2} \mathrm{SO}_{4}$ increases from right to left. The theoretical isoline for pure $\left(\mathrm{NH}_{4}\right)_{2} \mathrm{SO}_{4}(\kappa$ app $=0.6)$ is also shown.

mass spectrometer (ATOFMS) and SEM/EDX, and of their soluble extracts using ion chromatography and ICP-MS, did not reveal the presence of any notable contaminants (Sullivan et al., 2009). However, we were unable to rule out the presence of small amounts of sufficiently soluble carbonates including $\mathrm{K}_{2} \mathrm{CO}_{3}$ or $\mathrm{Na}_{2} \mathrm{CO}_{3}$.

To investigate the $\mathrm{CCN}$ activity of calcium-rich dust particles internally mixed with organic diacids, such as those observed during ACE-Asia (Sullivan and Prather, 2007), activation curves were determined for calcium oxalate monohydrate $\left(\mathrm{CaC}_{2} \mathrm{O}_{4} \cdot \mathrm{H}_{2} \mathrm{O}, \mathrm{COH}\right)$ particles. The dry-generated $\mathrm{COH}$ produced broad activation curves (Fig. 4). The reasons for this are unknown, and similar broad activation curves have been observed for other resuspended mineral dust samples (Koehler, 2007). This could be a result of chemical heterogeneity within the dry powder, or large variations in particle shape between particles of the same mobility diameter, causing a range of physical diameters to be selected by the DMA. As a result these curves are more difficult to fit, introducing greater uncertainty into the determination of the critical diameter or supersaturation. Drygenerated $\mathrm{COH}$ had an estimated $\kappa_{\text {app }}=0.048 \pm 0.013$. The small measured hygroscopicity of dry $\mathrm{COH}$ compared to oxalic acid $\left(\kappa_{\text {app }}=0.50 \pm 0.05\right)$ is attributed to its low solubility $\left(0.0061 \mathrm{~g} \mathrm{~L}^{-1}\right)$, which is similar to that of calcium carbonate $\left(0.0058 \mathrm{~g} \mathrm{~L}^{-1}\right)$. Therefore $\mathrm{COH}$ should produce particles with hygroscopicity near $\kappa_{\mathrm{app}} \sim 0.001$, similar to that 
Table 2. CCN activation properties and hygroscopicities of calcium minerals.

\begin{tabular}{|c|c|c|c|c|}
\hline compound & $*$ & $D_{\text {dry }}(\mathrm{nm})$ & $s_{c}(\%)$ & $\kappa^{\mathrm{a}}$ \\
\hline \multirow{4}{*}{$\begin{array}{l}\mathrm{CaCl}_{2} \cdot 2 \mathrm{H}_{2} \mathrm{O} \\
\text { (wet) }\end{array}$} & $S$ & 75.0 & 0.265 & 0.46 \\
\hline & $\mathrm{S}$ & 100.0 & 0.173 & 0.45 \\
\hline & $S$ & 125.0 & 0.126 & 0.44 \\
\hline & D & 154.0 & 0.078 & 0.58 \\
\hline \multirow{5}{*}{$\begin{array}{l}\mathrm{Ca}\left(\mathrm{NO}_{3}\right)_{2} \\
\text { (wet) }\end{array}$} & $S$ & 75.0 & 0.244 & 0.55 \\
\hline & $S$ & 100.0 & 0.171 & 0.47 \\
\hline & $\mathrm{S}$ & 125.0 & 0.126 & 0.44 \\
\hline & $\mathrm{D}$ & 152.0 & 0.078 & 0.64 \\
\hline & $\mathrm{b}$ & 89 & 0.110 & 1.25 \\
\hline \multirow{4}{*}{$\begin{array}{l}\mathrm{CaSO}_{4} \\
\text { (dry) }\end{array}$} & $\mathrm{S}$ & 150.0 & 0.885 & 0.0024 \\
\hline & $S$ & 200.0 & 0.683 & 0.0015 \\
\hline & $\mathrm{D}$ & 213.5 & 0.640 & 0.0014 \\
\hline & $\mathrm{S}$ & 300.0 & 0.435 & 0.0013 \\
\hline \multirow{5}{*}{$\begin{array}{l}\text { Solvay } \mathrm{CaCO}_{3} \\
\text { (dry) }\end{array}$} & $\mathrm{S}$ & 150.0 & 0.938 & 0.0018 \\
\hline & $\mathrm{S}$ & 200.0 & 0.730 & 0.0011 \\
\hline & $\mathrm{D}$ & 232.1 & 0.640 & 0.0009 \\
\hline & $\mathrm{S}$ & 250.0 & 0.580 & 0.0009 \\
\hline & $\mathrm{S}$ & 300.0 & 0.479 & 0.0008 \\
\hline \multirow{6}{*}{$\begin{array}{l}\mathrm{OMYA} \mathrm{CaCO}_{3} \\
\mathrm{CaC}_{2} \mathrm{O}_{4} \cdot \mathrm{H}_{2} \mathrm{O} \\
\text { (dry) }\end{array}$} & $\mathrm{b}$ & 100.0 & $\sim 0.55^{\mathrm{b}}$ & 0.043 \\
\hline & $\mathrm{S}$ & 100.0 & 0.487 & 0.056 \\
\hline & $\mathrm{D}$ & 123.63 & 0.363 & 0.054 \\
\hline & $\mathrm{D}$ & 140.28 & 0.363 & 0.036 \\
\hline & $\mathrm{S}$ & 150.0 & 0.253 & 0.062 \\
\hline & $S$ & 200.0 & 0.224 & 0.033 \\
\hline \multirow{3}{*}{$\begin{array}{l}\mathrm{C}_{2} \mathrm{O}_{4} \mathrm{H}_{2} \\
\text { (wet) }\end{array}$} & $S$ & 50.0 & 0.449 & 0.54 \\
\hline & $\mathrm{D}$ & 58.6 & 0.363 & 0.52 \\
\hline & $\mathrm{S}$ & 100.0 & 0.176 & 0.44 \\
\hline
\end{tabular}

*Scan type: S, supersaturation scan; D, dry diameter scan. ${ }^{\text {a }}$ Singleparameter apparent hygroscopicity, $\kappa_{\text {app }}$, derived from CCN activation curves. ${ }^{b}$ Data from Gibson et al. (2006); $s_{c}$ estimated from their Fig. 3.

measured for dry calcium carbonate. The particles would have to contain mass fractions of soluble contaminants on the order of $>10 \%$ to exhibit $\kappa_{\text {app }}=0.048 \pm 0.013$. It is possible that dissolved calcium oxalate may be surface active and therefore reduce the surface tension at the air-solute interface, thus decreasing the activation barrier. We calculate that a large reduction in surface tension from $0.072 \mathrm{~J} \mathrm{~m}^{-2}$ (pure water) to $0.029 \mathrm{~J} \mathrm{~m}^{-2}$ would be required to produce particles with $\kappa_{\text {app }}=0.048$. This reduction in surface tension is on the upper end for surface active organic compounds considered in CCN activation (Facchini et al., 2000). For example, adipic acid, azelaic acid, and succinic acid have surface tensions of $0.064,0.061$, and $0.065 \mathrm{~J} \mathrm{~m}^{-2}$, while nonanoic acid has a surface tension of $0.030 \mathrm{~J} \mathrm{~m}^{-2}$ (Broekhuizen et al., 2004). However, Nancollas and Wu (1998) measured the surface tension of $\mathrm{COH}$ to be $0.0324 \mathrm{~J} \mathrm{~m}^{-2}$ using a thin layer wicking method. As this is close to the surface tension we calculated to be necessary to match observations, reduced surface tension may explain the higher-than-expected apparent hygroscopicity of the dry calcium oxalate monohydrate.

Figure 5 compares the $\mathrm{CCN}$ properties of the calcium mineral particles described above in $s_{c}$ - $D_{\text {dry }}$ space with $\kappa$ isolines overlain. Dry-generated $\mathrm{CaCO}_{3}$ and $\mathrm{CaSO}_{4}$ demonstrated low apparent hygroscopicity and thus poor $\mathrm{CCN}$ activation potential, approaching the $\kappa=0$ isoline. $\mathrm{CaCl}_{2}$, $\mathrm{Ca}\left(\mathrm{NO}_{3}\right)_{2}$, and $\mathrm{C}_{2} \mathrm{O}_{4} \mathrm{H}_{2}$ approach the hygroscopicity of $\left(\mathrm{NH}_{4}\right)_{2} \mathrm{SO}_{4}\left(\kappa_{\text {app }}=\kappa\right.$ intr $\left.=0.61\right)$. Dry-generated $\mathrm{CaC}_{2} \mathrm{O}_{4} \cdot \mathrm{H}_{2} \mathrm{O}$ has $\kappa_{\text {app }} \sim 0.048 \pm 0.013$, its hygroscopicity lies in-between that of the other systems.

In Fig. 5 we also include isolines for pure $\mathrm{CaCO}_{3}$ and $\mathrm{CaSO}_{4}$, and their mixtures with a hygroscopic soluble contaminant with $\kappa_{\text {intr }}=0.6$ and $C=0.43$, representative of ammonium sulphate (and similar to calcium chloride, calcium nitrate, or oxalic acid), that take into account limited solubility (Eq. 4). The volume fraction of contaminant increases from right to left. Since almost no $\mathrm{CaCO}_{3}$ has dissolved in all these cases, the activation lines obtained for these mixed particles are almost completely determined by the sufficiently soluble substance alone. Our measurements of drygenerated $\mathrm{CaCO}_{3}$ and $\mathrm{CaSO}_{4}$ are consistent with the presence of very small volume fractions of soluble hygroscopic material, which produce a detectable increase in the particle's hygroscopicity and a subsequent decrease in its critical supersaturation (Kelly et al., 2007; Roberts et al., 2002). It is typically very difficult to generate uncontaminated insoluble laboratory particles, and this very small degree of $\sim 0.1 \%$ contamination that we observed is likely unavoidable and may already be present at the mineral powder's manufacturing source.

Multilayer adsorption models have been recently proposed to describe the activation of insoluble particles such as some of the minerals considered here (Henson, 2007; Sorjamaa and Laaksonen, 2007). Lines of constant hygroscopicity that we derived from the framework of Sorjamaa and Laaksonen (2007) had very shallow slopes in $s_{c}$ - $D_{\text {dry }}$ space that could not be consistently fit to our experimental results for $\mathrm{CaCO}_{3}$ or $\mathrm{CaSO}_{4}$. Alternatively, the formulations suggested by Henson (2007) could be used, but the slopes of the best fits using that approach could not be distinguished from the slopes of the $s_{c}-D_{\text {dry }}$ relationships obtained from traditional Köhler theory. The upper bound of $\Delta \mathrm{G}=33.6 \mathrm{~kJ} / \mathrm{mole}$ given by Henson produces an isoline from his adsorption model corresponding to $\kappa_{\text {app }} \sim 0.001$, which approximates the $\mathrm{CaCO}_{3}$ or $\mathrm{CaSO}_{4}$ data. Therefore, activation of these insoluble minerals can be described simply by the Kelvin effect in traditional Köhler theory, or by Henson's adsorption isotherm model. If activation proceeded via adsorption we do not need to invoke contamination to explain $\kappa_{\text {app }} \sim 0.001$; either mechanism is plausible.

The interplay between chemical mixing state and solubility is summarized in Table 3, which lists the solubilities of various cation-anion pairs for typical mineral dust components. Sparingly soluble and insoluble compounds are 
Table 3. Solubilities ${ }^{\mathrm{a}}$, estimated intrinsic hygroscopicities ${ }^{\mathrm{b}}$, and measured apparent hygroscopicities of various inorganic salts ${ }^{\mathrm{c}}$.

\begin{tabular}{|c|c|c|c|c|c|}
\hline & $\mathrm{Ca}^{2+}$ & $\mathrm{Mg}^{2+}$ & $\mathrm{K}^{+}$ & $\mathrm{Na}^{+}$ & $\mathrm{NH}_{4}{ }^{+}$ \\
\hline $\mathrm{CO}_{3}{ }^{2-}$ & $\mathrm{S}=0.0058$ & $1.8^{20}$ & 1110 & 307 & $1000^{15}$ \\
& $\kappa=0.97^{\mathrm{b}} / 0.001^{\mathrm{d}}$ & 1.30 & 0.90 & 1.30 & 0.84 \\
\hline $\mathrm{SO}_{4}{ }^{2-}$ & 2.05 & 357 & 120 & 281 & 764 \\
& $0.78 / 0.002^{\mathrm{d}}$ & 0.80 & 0.83 & $1.03 / 0.80^{\mathrm{e}}$ & $0.72 / 0.61^{\mathrm{e}}$ \\
\hline $\mathrm{NO}_{3}{ }^{-}$ & 1440 & 712 & 383 & 912 & 2130 \\
& $0.82 / 0.51^{\mathrm{d}}$ & 0.84 & 0.88 & $0.96 / 0.88^{\mathrm{e}}$ & $0.77 / 0.67^{\mathrm{e}}$ \\
\hline $\mathrm{Cl}^{-}$ & 813 & 560 & 355 & 360 & 395 \\
& $1.05 / 0.48^{\mathrm{d}}$ & 1.32 & 0.89 & $1.34 / 1.28^{\mathrm{e}}$ & 1.02 \\
\hline Oxalate & $0.0061^{20}$ & 0.38 & $364^{20}$ & 36.1 & 52.0 \\
& $0.62 / 0.048^{\mathrm{d}}$ & 0.79 & 0.42 & 0.94 & 0.65 \\
\hline
\end{tabular}

a All solubilities $\left(\mathrm{g} \mathrm{L}^{-1}\right)$ taken from the $\mathrm{CRC}$ Handbook of Chemistry and Physics, 88 th edition, for $25^{\circ} \mathrm{C}$. Superscript indicates solubility at $T$ other than $25^{\circ} \mathrm{C}$.

${ }^{\mathrm{b}}$ Calculated with Eq. (5) using values listed in Table 1 or else in the CRC Handbook for the anhydrous state.

${ }^{\mathrm{c}}$ Laboratory generated particles may be composed of salts in metastable states in some cases.

$\mathrm{d}$ Measured apparent hygroscopicity from this work (in italics).

e Hygroscopicity measured from CCN activation experiments summarized by Petters and Kreidenweis (2007).

indicated with shading. We calculate $\kappa_{\text {intr }}$ for the anhydrous forms in all cases, while recognizing that hydrated states do form for some of the cation-anion pairs shown and that these will have slightly smaller $\kappa_{\text {intr }}$. The estimated intrinsic hygroscopicities via Raoult's law (Eq. (5)) are $>0.4$ for all these mixing states. However, the large differences in solubility affect whether the observed apparent hygroscopicity of each compound reflects its intrinsic hygroscopicity, or approaches $\kappa_{\mathrm{app}}=0$ during activation. Our experimental observations of calcium mineral particles largely confirm the expected links between solubilities and observed apparent hygroscopicities, with calcium carbonate, sulphate, and oxalate approximately described by $\kappa_{\text {app }}=0$. Although we did not measure them, based on our findings for calcium minerals, we expect the $\mathrm{CCN}$ activities of magnesium carbonate and oxalate to also approach $\kappa_{\text {app }}=0$. Other forms of magnesium minerals, calcium nitrate and chloride, and all of the potassium, sodium, and ammonium compounds, are soluble enough that we expect them to exhibit hygroscopic behaviour similar to ammonium sulphate, i.e. $\kappa_{\mathrm{app}}=\kappa_{\text {intr }}$. Note that sulphate and oxalate compounds represent atmospherically processed forms of mineral dust and yet are not always soluble enough to express their large intrinsic hygroscopicities. The experimental $\mathrm{CCN}$ data summarized in Fig. 5 are in direct agreement with these expected trends in apparent hygroscopicity.

\section{Atmospheric implications}

The atmospheric processing of mineral dust particles is typically expected to increase their hygroscopicity and $\mathrm{CCN}$ activity (Fan et al., 2004; Gibson et al., 2006; Levin et al., 1996; Perry et al., 2004; Roberts et al., 2006; Sullivan et al., 2007a). This is because heterogeneous reactions with reactive gases including nitric, hydrochloric, and sulphuric acids can convert insoluble carbonates into sparingly or sufficiently soluble compounds that play an important role in hygroscopic growth and cloud droplet activation. Condensation or coagulation of soluble secondary aerosol compounds may similarly increase the dust's hygroscopicity. However, field and laboratory studies are required to validate this. From our laboratory measurements of the $\mathrm{CCN}$ ability of various calcium minerals, we have demonstrated that one common mineral representative of chemically aged dust particles calcium sulphate - has poor CCN activation potential, behaving similarly to calcium carbonate which is a proxy for fresh unaged mineral dust. Another proxy for aged dust, calcium oxalate monohydrate, has only moderate CCN activity. Thus, it is possible for mineral dust particles to undergo extensive chemical reactions during atmospheric transport and yet remain non-hygroscopic, due to the formation of low solubility products (Table 3). It is therefore incorrect to assume that all mineral dust particles will become more hygroscopic and $\mathrm{CCN}$-active during the course of atmospheric processing. The predominant chemical reaction and dust mineralogy must be known to reliably predict the resulting 
hygroscopicity of the aged mineral dust particles. If calciterich dust particles instead react with nitrate or chloride precursors, such as $\mathrm{NO}_{\mathrm{x}}, \mathrm{HNO}_{3}, \mathrm{~N}_{2} \mathrm{O}_{5}$, or $\mathrm{HCl}$, the resulting calcium nitrate and chloride salts are highly hygroscopic and will result in more $\mathrm{CCN}$-active aged dust particles. As mineralogy varies greatly between dust regions (Claquin et al., 1999), the source of the dust could also have a large influence on its resulting hygroscopicity after atmospheric aging.

Shi et al. (2008) have recently reported the differing hygroscopicities of individual supermicron ambient Asian mineral dust particles collected in Japan. They observed that dust particles that did not contain sulphate or nitrate (i.e. unreacted dust) and sulphate-rich dust particles (i.e. aged dust) did not experience hygroscopic growth even at $90 \%$ RH. Nitrate-rich dust particles, however, appeared to deliquesce at as low as $15 \% \mathrm{RH}$, as has been previously reported (Krueger et al., 2003; Laskin et al., 2005). Our laboratory experiments agree with their field measurements and demonstrate a segregated hygroscopic state caused by the segregated chemical mixing state of sulphate from nitrate and chloride in individual aged dust particles (Sullivan et al., 2007a).

Calcium oxalate monohydrate was observed to be significantly less $\mathrm{CCN}$-active than oxalic acid. Oxalic acid is typically the dominant component of water soluble organic aerosol mass and has been studied as a large potential contributor to aerosol hygroscopicity and CCN activity (Prenni et al., 2001). In the Asian aerosol sampled during ACEAsia we found that oxalic acid was predominantly internally mixed with mineral dust particles (Sullivan and Prather, 2007). This mixing state could result in the oxalate forming low solubility complexes with divalent cations such as $\mathrm{Ca}^{2+}$ that are enriched in Asian dust. This would reduce the solubility of the oxalic acid and this could in turn reduce the apparent hygroscopicity and $\mathrm{CCN}$-activity of oxalatecontaining particles, as we observed here. The conversion of calcium carbonate to calcium oxalate through reaction with oxalic acid will also reduce the mass of $\mathrm{CaCO}_{3}$ available to be converted to more soluble and hygroscopic forms such as $\mathrm{CaCl}_{2}$ and $\mathrm{Ca}\left(\mathrm{NO}_{3}\right)_{2}$. A similar effect is produced by the conversion of calcium carbonate to calcium sulphate through reaction with sulphur oxides.

In discussing the $\mathrm{CCN}$ activation potential of atmospheric mineral dust particles, we must also consider the role of ammonium internally mixed with dust, which we observed during ACE-Asia (Sullivan et al., 2007a). We found that ammonium was frequently internally mixed with aged mineral dust particles and appeared to have formed through neutralizing secondary acids that had accumulated in the dust. Ammonium was most strongly associated with sulphate, as expected due to the stability of ammonium sulphate. If a small fraction of sulphate is in the form of $\left(\mathrm{NH}_{4}\right)_{2} \mathrm{SO}_{4}$ instead of $\mathrm{CaSO}_{4}$, this can increase the dust particle's hygroscopicity due to the higher solubility of $\left(\mathrm{NH}_{4}\right)_{2} \mathrm{SO}_{4}$ (Fig. 5). During ACE-Asia, sulphate-rich mineral dust particles were primarily associated with submicron iron- and aluminosilicate- rich mineral particles, while nitrate and chloride were enriched in supermicron calcite-rich particles (Sullivan et al., 2007a). However, an appreciable fraction of Ca-rich dust particles did contain smaller but still significant sulphate signals. These likely represent particles that are primarily calcium sulphate, while the aged Fe/Al-rich dust particles with larger sulphate and ammonium signals are indicative of dust particles internally mixed with ammonium sulphate. Based on the laboratory $\mathrm{CCN}$ data presented above, we predict that these two chemical forms of aged sulphate-dust particles would have very different $\mathrm{CCN}$-activity. The observation of Shi et al. (2008) of aged sulphate-rich mineral dust particles that remained non-hygroscopic is further confirmation that this is a realistic physiochemical state for aged dust particles in the atmosphere. For nitrate- and chloride-rich aged dust particles, however, the precise chemical form of these acid reaction products will be less important because most atmospherically-relevant nitrate and chloride salts are sufficiently soluble and hygroscopic, regardless of their associated cation (Table 3) (Kelly et al., 2007). The addition of trace amounts of water soluble species (e.g. $\left.\left(\mathrm{NH}_{4}\right)_{2} \mathrm{SO}_{4}\right)$ exerts the largest increase in $\mathrm{CCN}$ activity on dust particles that are initially non-hygroscopic and insoluble. Hence, the chemical pathways associated with atmospheric aging effectively dictate the cloud nucleation potential of atmospheric dust particles. Our findings provide further motivation for the need to determine both the mixing state and relative amounts of various secondary species in individual mineral dust and other particle types to accurately predict the aged aerosol's hygroscopicity and $\mathrm{CCN}$-activity.

In this discussion the important role of particle hygroscopicity in determining other significant particle properties should also be emphasized. Particulate-phase water alters the dust particle's size, refractive index, and shape, which affect the radiative properties of dust and thus their direct climate effects (Satheesh and Moorthy, 2005). The water content of hygroscopic dust particles may provide a medium for multiphase chemical reactions and change the solubility of important components in mineral dust such as iron. The increased $\mathrm{CCN}$ activity of some aged mineral dust particles will also increase their rate of wet scavenging which affects the environmental mass balance and transport of mineral dust (Fan et al., 2004). Finally, the dust's chemical mixing state will also influence its ice nucleation ability. Insoluble, hydrophobic particles can often nucleate ice at warmer temperatures via heterogeneous nucleation, but this is highly dependent on the mineralogy. The few available freezing studies of calcite and gypsum $\left(\mathrm{CaSO}_{4} \cdot 2 \mathrm{H}_{2} \mathrm{O}\right)$ indicate that they have relatively poor heterogeneous nucleation ability compared to aluminosilicate clay minerals (Eastwood et al., 2008; Zimmermann et al., 2008). The freezing properties of calcium oxalate monohydrate, calcium nitrate, and calcium chloride have not been studied, to our knowledge. Our single particle measurements during ACE-Asia revealed that mineral dust composed one-quarter of the total sub-500 nm particle counts 
in remote clean marine environments. This contribution was even larger closer to Asia and was extremely high during an Asian dust storm. The large role that mineral dust particles can play in composing the potential submicron $\mathrm{CCN}$ population should therefore be revisited.

\section{Conclusions}

The $\mathrm{CCN}$ activation properties of various pure calcium minerals were measured as proxies for fresh and atmospherically aged calcium-rich mineral dust particles. A single parameter for particle hygroscopicity, $\kappa$, was used to interpret the experimental data. A framework for accounting for the limiting effect of solubility on a particle's observed hygroscopicity was introduced through the concepts of apparent and intrinsic hygroscopicity. A particle's apparent hygroscopicity is that which is experimentally observed. It is equal to its intrinsic hygroscopicity if the particle is completely dissolved before activation. Low solubility components limit the full expression of a compound's intrinsic hygroscopicity as its observed apparent hygroscopicity. Changes in surface tension can produce similar differences between apparent and intrinsic hygroscopicity. This framework can be used to describe any complex particle system, including mixtures of inorganic and organic compounds with varying solubility.

The particle generation method can cause significant changes in the apparent hygroscopicity of insoluble mineral particles. Atomization of insoluble powders was observed to produce particles with much larger hygroscopicities than expected (Sullivan et al., 2009). Therefore, only the drygenerated insoluble particles and atomized sufficiently soluble particles were considered here to infer the hygroscopicity they will likely display in the atmosphere. Calcium oxalate monohydrate was moderately $\mathrm{CCN}$ active and more hygroscopic $\left(\kappa_{\text {app }}=0.048\right)$ than its solubility and intrinsic hygroscopicity would predict, but still significantly less hygroscopic than oxalic acid $\left(\kappa_{\mathrm{app}}=0.50\right)$. The moderate apparent hygroscopicity could be due to a reduction in surface tension, or the presence of significant amounts of soluble contaminants.

We found two general states of particle hygroscopicity:

1. Sufficiently soluble minerals, i.e. $\mathrm{CaCl}_{2}$ and $\mathrm{Ca}\left(\mathrm{NO}_{3}\right)_{2}$, that are hygroscopic $\left(\kappa_{\mathrm{app}} \sim 0.5\right)$ and have critical supersaturations similar to $\left(\mathrm{NH}_{4}\right)_{2} \mathrm{SO}_{4}\left(\kappa_{\text {app }}=\kappa_{\text {intr }}=0.61\right)$.

2. Insoluble minerals, i.e. $\mathrm{CaCO}_{3}$ and $\mathrm{CaSO}_{4}$, with low apparent hygroscopicity $\left(\kappa_{\mathrm{app}} \sim 0.001\right)$, poor $\mathrm{CCN}$ activation ability, and critical supersaturations consistent with deliquescence-limited activation (Kelvin limit).

As we have shown here, the chemical form of the reactive gases that reacted and mixed with dust to produce secondary compounds must be known to accurately predict the hygroscopicity and $\mathrm{CCN}$ activity of the resulting mineral mixture.
Table 3 demonstrates that it is incorrect to assume that all chemical reactions that process dust in the atmosphere produce soluble reaction products that increase the $\mathrm{CCN}$ ability of dust. Insoluble reaction products such as calcium sulphate are frequently observed in aged mineral dust particles, have low CCN-activity, and should also be considered in evaluating the indirect climate effects of dust on cloud properties (Kelly et al., 2007; Shi et al., 2008). The proxies for fresh and aged calcium mineral particles studied here provide upper and lower limits to expected atmospheric dust hygroscopicity. Koehler et al. (2009) found the hygroscopicity of authentic mineral dust samples to be represented by $0.01 \leq \kappa \leq 0.08$, which lies in the middle of the values reported here. As calcite is present in variable but significant amounts in surface soils found in all major dust source regions, the chemical mixing states and corresponding hygroscopicities presented here should be applicable to a considerable fraction of atmospheric dust particle mineralogy.

Acknowledgements. RCS, MJKM, and KAP acknowledge funding support from NSF (Fund\# ATM-0625526) for this research. We thank Alex Laskin for valuable discussions and Kirsten Koehler for sharing experimental data and useful information with us.

Edited by: D. Cziczo

\section{References}

Albrecht, B. A.: Aerosols, Cloud Microphysics, and Fractional Cloudiness, Science, 245, 1227-1230, 1989.

Andreae, M. O. and Rosenfeld, D.: Aerosol-cloud-precipitation interactions. Part 1. The nature and sources of cloud-active aerosols, Earth Sci. Rev., 89, 13-41, 2008.

Bilde, M. and Svenningsson, B.: CCN activation of slightly soluble organics: the importance of small amounts of inorganic salt and particle phase, Tellus B, 56, 128-134, 2004.

Broekhuizen, K., Kumar, P. P., and Abbatt, J. P. D.: Partially soluble organics as cloud condensation nuclei: Role of trace soluble and surface active species, Geophys. Res. Lett., 31, L01107, doi:10.1029/2003GL018203, 2004.

Carrico, C. M., Kus, P., Rood, M. J., Quinn, P. K., and Bates, T. S.: Mixtures of pollution, dust, sea salt, and volcanic aerosol during ACE-Asia: Radiative properties as a function of relative humidity, J. Geophys. Res., 108, 8650, doi:10.1029/2003JD003405, 2003.

Claquin, T., Schulz, M., and Balkanski, Y. J.: Modeling the mineralogy of atmospheric dust sources, J. Geophys. Res., 104, 2224322256, 1999.

Cohen, M. D., Flagan, R. C., and Seinfeld, J. H.: Studies of concentrated electrolyte solutions using the electrodynamic balance. 1 . Water activities for single-electrolyte solutions, J. Phys. Chem., 91, 4563-4574, 1987.

DeMott, P. J., Cziczo, D. J., Prenni, A. J., Murphy, D. M., Kreidenweis, S. M., Thomson, D. S., Borys, R., and Rogers, D. C.: Measurements of the concentration and composition of nuclei for cirrus formation, Proc. Natl. Acad. Sci. USA, 100, 14655-14660, 10.1073/pnas.2532677100, 2003. 
Eastwood, M. L., Cremel, S., Gehrke, C., Girard, E., and Bertram, A. K.: Ice nucleation on mineral dust particles: Onset conditions, nucleation rates and contact angles, J. Geophys. Res., 113, D22203, doi:10.1029/2008jd010639, 2008.

Facchini, M. C., Decesari, S., Mircea, M., Fuzzi, S., and Loglio, G.: Surface tension of atmospheric wet aerosol and cloud/fog droplets in relation to their organic carbon content and chemical composition, Atmos. Environ., 34, 4853-4857, 2000.

Falkovich, A. H., Schkolnik, G., Ganor, E., and Rudich, Y.: Adsorption of organic compounds pertinent to urban environments onto mineral dust particles, J. Geophys. Res., 109, D02208, doi:10.1029/2003JD003919, 2004.

Fan, S. M., Horowitz, L. W., Levy, H., and Moxim, W. J.: Impact of air pollution on wet deposition of mineral dust aerosols, Geophys. Res. Lett., 31, L02104, doi:10.1029/2003GL018501, 2004.

Gibson, E. R., Hudson, P. K., and Grassian, V. H.: Aerosol chemistry and climate: Laboratory studies of the carbonate component of mineral dust and its reaction products, Geophys. Res. Lett., 33, L13811, doi:10.1029/2006GL026386, 2006.

Henson, B. F.: An adsorption model of insoluble particle activation: Application to black carbon, J. Geophys. Res., 112, D24S16, doi:10.1029/2007jd008549, 2007.

IPCC: Climate Change 2007: The Physical Science Basis. Contribution of Working Group I to the Fourth Assessment Report of the Intergovernmental Panel on Climate Change, edited by: Solomon, S., Qin, D., Manning, M., Chen, Z., Marquiz, M., Averyt, K. B., Tignor, M., and Miller, H. L., Cambridge University Press, Cambridge, 2007.

Jeong, G. Y. and Chun, Y.: Nanofiber calcite in Asian dust and its atmospheric roles, Geophys. Res. Lett., 33, L24802, doi:10.1029/2006GL028280, 2006.

Jeong, G. Y.: Bulk and single-particle mineralogy of Asian dust and a comparison with its source soils, J. Geophys. Res., 113, D02208, doi:10.1029/2007JD008606, 2008.

Kelly, J. T. and Wexler, A. S.: Thermodynamics of carbonates and hydrates related to heterogeneous reactions involving mineral aerosol, J. Geophys. Res., 110, D11201, doi:10.1029/2004JD005583, 2005.

Kelly, J. T., Chuang, C. C., and Wexler, A. S.: Influence of dust composition on cloud droplet formation, Atmos. Environ., 41, 2904-2916, 2007.

Koehler, K.: The impact of natural dust aerosol on warm and cold cloud formation, Department of Atmospheric Science, Colorado State University, Fort Collins, USA, 2007.

Koehler, K., Kreidenweis, S. M., DeMott, P. J., Petters, M. D., Prenni, A. J., and Carrico, C. M.: Hygroscopicity and cloud droplet activation of mineral dust aerosol, Geophys. Res. Lett., 36, L08805, doi:10.1029/2009GL037348, 2009.

Koehler, K. A., Kreidenweis, S. M., DeMott, P. J., Prenni, A. J., Carrico, C. M., Ervens, B., and Feingold, G.: Water activity and activation diameters from hygroscopicity data - Part II: Application to organic species, Atmos. Chem. Phys., 6, 795-809, 2006, http://www.atmos-chem-phys.net/6/795/2006/.

Koehler, K. A., Kreidenweis, S. M., DeMott, P. J., Prenni, A. J., and Petters, M. D.: Potential impact of Owens (dry) Lake dust on warm and cold cloud formation, J. Geophys. Res., 112, D12210, doi:10.1029/2007JD008413, 2007.

Kreidenweis, S. M., Petters, M. D., and DeMott, P. J.: Deliquescence-controlled activation of organic aerosols, Geo- phys. Res. Lett., 33, L06801, doi:10.1029/2005GL024863, 2006.

Krueger, B. J., Grassian, V. H., Laskin, A., and Cowin, J. P.: The transformation of solid atmospheric particles into liquid droplets through heterogeneous chemistry: Laboratory insights into the processing of calcium containing mineral dust aerosol in the troposphere, Geophys. Res. Lett., 30, 1148, doi:10.1029/2002GL016563, 2003.

Krueger, B. J., Grassian, V. H., Cowin, J. P., and Laskin, A.: Heterogeneous chemistry of individual mineral dust particles from different dust source regions: the importance of particle mineralogy, Atmos. Environ., 38, 6253-6261, 2004.

Laskin, A., Iedema, M. J., Ichkovich, A., Graber, E. R., Taraniuk, I., and Rudich, Y.: Direct observation of completely processed calcium carbonate dust particles, Faraday Discussions, 130, 453468, 2005.

Lee, Y. H., Chen, K., and Adams, P. J.: Development of a global model of mineral dust aerosol microphysics, Atmos. Chem. Phys., 9, 2441-2458, 2009,

http://www.atmos-chem-phys.net/9/2441/2009/.

Levin, Z., Ganor, E., and Gladstein, V.: The effects of desert particles coated with sulfate on rain formation in the eastern Mediterranean, J. Appl. Meteorol., 35, 1511-1523, 1996.

Lohmann, U. and Feichter, J.: Global indirect aerosol effects: a review, Atmos. Chem. Phys., 5, 715-737, 2005, http://www.atmos-chem-phys.net/5/715/2005/.

Matsuki, A., Iwasaka, Y., Shi, G. Y., Zhang, D. Z., Trochkine, D., Yamada, M., Kim, Y. S., Chen, B., Nagatani, T., Miyazawa, T., Nagatani, M., and Nakata, H.: Morphological and chemical modification of mineral dust: Observational insight into the heterogeneous uptake of acidic gases, Geophys. Res. Lett., 32, L22806, doi:10.1029/2005GL024176, 2005.

McFiggans, G., Artaxo, P., Baltensperger, U., Coe, H., Facchini, M. C., Feingold, G., Fuzzi, S., Gysel, M., Laaksonen, A., Lohmann, U., Mentel, T. F., Murphy, D. M., O’Dowd, C. D., Snider, J. R., and Weingartner, E.: The effect of physical and chemical aerosol properties on warm cloud droplet activation, Atmos. Chem. Phys., 6, 2593-2649, 2006, http://www.atmos-chem-phys.net/6/2593/2006/.

Nancollas, G. H. and Wu, W. J.: The surface, interfacial and electrokinetic properties of biominerals, J. Disp. Sci. Technol., 19, 723-738, 1998.

Perry, K. D., Cliff, S. S., and Jimenez-Cruz, M. P.: Evidence for hygroscopic mineral dust particles from the Intercontinental Transport and Chemical Transformation Experiment, J. Geophys. Res., 109, D23S28, doi:10.1029/2004JD004979, 2004.

Petters, M. D., Snider, J. R., Stevens, B., Vali, G., Faloona, I., and Russell, L. M.: Accumulation mode aerosol, pockets of open cells, and particle nucleation in the remote subtropical $\mathrm{Pa}-$ cific marine boundary layer, J. Geophys. Res., 111, D02206, doi:10.1029/2004JD005694, 2006.

Petters, M. D. and Kreidenweis, S. M.: A single parameter representation of hygroscopic growth and cloud condensation nucleus activity, Atmos. Chem. Phys., 7, 1961-1971, 2007, http://www.atmos-chem-phys.net/7/1961/2007/.

Petters, M. D., Prenni, A. J., Kreidenweis, S. M., and DeMott, P. J.: On measuring the critical diameter of cloud condensation nuclei using mobility selected aerosol, Aerosol Sci. Technol., 41, 907913, 2007.

Petters, M. D. and Kreidenweis, S. M.: A single parameter repre- 
sentation of hygroscopic growth and cloud condensation nucleus activity - Part 2: Including solubility, Atmos. Chem. Phys., 8, 6273-6279, 2008,

http://www.atmos-chem-phys.net/8/6273/2008/.

Plummer, L. N. and Busenberg, E.: The Solubilities of Calcite, Aragonite and Vaterite in $\mathrm{CO}_{2}-\mathrm{H}_{2} \mathrm{O}$ Solutions between 0Degrees-C and 90-Degrees-C, and an Evaluation of the Aqueous Model for the System $\mathrm{CaCO}_{3}-\mathrm{CO}_{2}-\mathrm{H}_{2} \mathrm{O}$, Geochimica Et Cosmochimica Acta, 46, 1011-1040, 1982.

Prenni, A. J., DeMott, P. J., Kreidenweis, S. M., Sherman, D. E., Russell, L. M., and Ming, Y.: The effects of low molecular weight dicarboxylic acids on cloud formation, J. Phys. Chem. A, 105, 11240-11248, 2001.

Roberts, G., Mauger, G., Hadley, O., and Ramanathan, V.: North American and Asian aerosols over the eastern Pacific Ocean and their role in regulating cloud condensation nuclei, J. Geophys. Res., 111, D13205, doi:10.1029/2005JD006661, 2006.

Roberts, G. C., Artaxo, P., Zhou, J. C., Swietlicki, E., and Andreae, M. O.: Sensitivity of CCN spectra on chemical and physical properties of aerosol: A case study from the Amazon Basin, J. Geophys. Res., 107, 8070, doi:10.1029/2001JD000583, 2002.

Roberts, G. C. and Nenes, A.: A continuous-flow streamwise thermal-gradient $\mathrm{CCN}$ chamber for atmospheric measurements, Aerosol Sci. Technol., 39, 206-221, 2005.

Rose, D., Gunthe, S. S., Mikhailov, E., Frank, G. P., Dusek, U., Andreae, M. O., and Pöschl, U.: Calibration and measurement uncertainties of a continuous-flow cloud condensation nuclei counter (DMT-CCNC): CCN activation of ammonium sulfate and sodium chloride aerosol particles in theory and experiment, Atmos. Chem. Phys., 8, 1153-1179, 2008, http://www.atmos-chem-phys.net/8/1153/2008/.

Rosenfeld, D., Rudich, Y., and Lahav, R.: Desert dust suppressing precipitation: A possible desertification feedback loop, Proc. Natl. Acad. Sci. USA, 98, 5975-5980, 2001.

Rosenfeld, D., Lohmann, U., Raga, G. B., kulmala, M., Fuzzi, S., Reissell, A., and Andreae, M. O.: Flood or Drought: How Do Aerosols Affect Precipitation?, Science, 321, 1309-1313, 2008.

Satheesh, S. K. and Moorthy, K. K.: Radiative effects of natural aerosols: A review, Atmos. Environ., 39, 2089-2110, 2005.

Shi, Z., Zhang, D., Hayashi, M., Ogata, H., Ji, H., and Fujiie, W.: Influences of sulfate and nitrate on the hygroscopic behaviour of coarse dust particles, Atmos. Environ., 42, 822-827, 2008.

Shi, Z. B., Shao, L. T., Jones, T. P., and Lu, S. L.: Microscopy and mineralogy of airborne particles collected during severe dust storm episodes in Beijing, China, J. Geophys. Res., 110, D01303, doi:10.1029/2004JD005073, 2005.

Shulman, M. L., Jacobson, M. C., Charlson, R. J., Synovec, R. E., and Young, T. E.: Dissolution behavior and surface tension effects of organic compounds in nucleating cloud droplets, Geophys. Res. Lett., 23, 277-280, 1996.

Sorjamaa, R. and Laaksonen, A.: The effect of $\mathrm{H}_{2} \mathrm{O}$ adsorption on cloud drop activation of insoluble particles: a theoretical framework, Atmos. Chem. Phys., 7, 6175-6180, 2007, http://www.atmos-chem-phys.net/7/6175/2007/.
Stith, J. L., Ramanathan, V., Cooper, W. A., Roberts, G. C., DeMott, P. J., Carmichael, G., Hatch, C. D., Adhikary, B., Twohy, C. H., Rogers, D. C., Baumgardner, D., Prenni, A. J., Campos, T., Gao, R., Anderson, J., and Feng, Y.: An overview of aircraft observations from the Pacific Dust Experiment campaign, J. Geophys. Res., 114, D05207, doi:10.1029/2008JD010924, 2009.

Sullivan, R. C., Guazzotti, S. A., Sodeman, D. A., and Prather, K. A.: Direct observations of the atmospheric processing of Asian mineral dust, Atmos. Chem. Phys., 7, 1213-1226, 2007a, http://www.atmos-chem-phys.net/7/1213/2007/.

Sullivan, R. C., Guazzotti, S. A., Sodeman, D. A., Tang, Y. H., Carmichael, G. R., and Prather, K. A.: Mineral dust is a sink for chlorine in the marine boundary layer, Atmos. Environ., 41, 7166-7179, 2007b.

Sullivan, R. C. and Prather, K. A.: Investigations of the diurnal cycle and mixing state of oxalic acid in individual particles in Asian aerosol outflow, Environ. Sci. Technol., 41, 8062-8069, 2007.

Sullivan, R. C., Moore, M. J. K., Petters, M. D., Kreidenweis, S. M., Roberts, G. C., Laskin, A., and Prather, K. A.: Impact of particle generation method on the apparent hygroscopicity of insoluble calcium minerals, Aerosol Sci. Technol., to be submitted, 2009.

Tang, I. N. and Fung, K. H.: Hydration and Raman scattering studies of levitated microparticles: $\mathrm{Ba}\left(\mathrm{NO}_{3}\right)_{2}, \mathrm{Sr}\left(\mathrm{NO}_{3}\right)_{2}$, and $\mathrm{Ca}\left(\mathrm{NO}_{3}\right)_{2}$, J. Chem. Phys., 106, 1653-1660, 1997.

Tang, Y. H., Carmichael, G. R., Seinfeld, J. H., Dabdub, D., Weber, R. J., Huebert, B., Clarke, A. D., Guazzotti, S. A., Sodeman, D. A., Prather, K. A., Uno, I., Woo, J. H., Yienger, J. J., Streets, D. G., Quinn, P. K., Johnson, J. E., Song, C. H., Grassian, V. H., Sandu, A., Talbot, R. W., and Dibb, J. E.: Three-dimensional simulations of inorganic aerosol distributions in east Asia during spring 2001, J. Geophys. Res., 109, D19S23, doi:10.1029/2003JD004201, 2004.

Twohy, C. H., Kreidenweis, S. M., Eidhammer, T., Browell, E. V., Heymsfield, A. J., Bansemer, A. R., Anderson, B. E., Chen, G., Ismail, S., DeMott, P. J., and Van den Heever, S. C.: Saharan dust particles nucleate droplets in eastern Atlantic clouds, Geophys. Res. Lett., 36, L01807, doi:10.1029/2008g1035846, 2009.

Twomey, S.: Influence of Pollution on Shortwave Albedo of Clouds, J. Atmos. Sci., 34, 1149-1152, 1977.

Usher, C. R., Michel, A. E., and Grassian, V. H.: Reactions on mineral dust, Chem. Rev., 103, 4883-4939, 2003.

Vlasenko, A., Sjogren, S., Weingartner, E., Gaggeler, H. W., and Ammann, M.: Generation of submicron Arizona test dust aerosol: Chemical and hygroscopic properties, Aerosol Sci. Technol., 39, 452-460, 2005.

Zimmermann, F., Weinbruch, S., Schutz, L., Hofmann, H., Ebert, M., Kandler, K., and Worringen, A.: Ice nucleation properties of the most abundant mineral dust phases, J. Geophys. Res., 113, D23204, doi:10.1029/2008jd010655, 2008. 